\title{
Patent foramen ovale closure review: decades of research and the evolution of the evidence
}

\author{
Ayodipupo S Oguntade ${ }^{1,2^{*}}$ and Mayowa Sefiu Oguntade ${ }^{3}$
}

\begin{abstract}
Background: A quarter of the population suffers from patent foramen ovale, a form of interatrial shunt. It has been linked to cryptogenic strokes and is a common cause of paradoxical embolism.

Main text: The benefit of closing the patent foramen ovale in cryptogenic stroke patients aged 18-60 years to prevent recurrent strokes, particularly in those with large shunts or associated atrial septal aneurysms, was recently demonstrated. It is a relatively safe procedure that necessitates post-operative anticoagulation, but it has been linked to new-onset atrial fibrillation of uncertain significance. The effectiveness of patent foramen closure depends on patient selection, and prediction scores such as the Risk of Paradoxical Embolism (RoPE) score should be used. Newer closure devices, such as bioabsorbable devices like the Biostar system and 'device-less' devices like the Noble Stitch, are becoming more common due to their lower operative risks. The use of such devices in future trials, as well as careful case selection, could improve the acceptability of patent foramen ovale closure in the general population, removing the need for perioperative anticoagulation.

Conclusion: Individuals aged 18-60 years with cryptogenic stroke who have adverse patent foramen ovale morphology on imaging should be offered patent foramen ovale closure, preferably using the newer closure devices. More studies are needed to determine the significance of periprocedural atrial fibrillation after device closure.
\end{abstract}

Keywords: Patent foramen ovale, Cryptogenic stroke, Patent foramen ovale closure devices, Patent foramen ovale occluders

\section{Background}

In the general population, patent foramen ovales (PFOs) are persistent interatrial shunts [1]. The prevalence has been estimated at $27 \%$ in an autopsy study [2], whilst echocardiographic studies indicate a prevalence of 10$15 \%$ under physiologic conditions [3]. They can be found alone or in combination with other congenital defects such as ventricular septal defects, patent ductus arteriosus and secundum atrial septal defects (ASDs) [4]. Its

\footnotetext{
* Correspondence: ayodipupooguntade@gmail.com

'Nuffield Department of Population Health, University of Oxford, Oxford, UK ${ }^{2}$ Division of Cardiology, Department of Medicine, University College Hospital, Ibadan, Nigeria

Full list of author information is available at the end of the article
}

association with cryptogenic strokes has sparked interest in PFO closure. The objective of this paper was to review the evidence for PFO device closure, its safety and adverse events, and patient selection for device closure. The review also discussed the role of newer closure devices in PFO closure.

\section{Clinical significance of PFO \\ Stroke risk}

About 100,000 strokes are diagnosed in the UK each year, with $85 \%$ of them being ischaemic in nature and up to $20 \%$ occurring in people under the age of 60 [5]. PFO remains the commonest association of cryptogenic stroke in young adults with up to half of cryptogenic

\section{Springer Open}

(๑) The Author(s). 2021 Open Access This article is licensed under a Creative Commons Attribution 4.0 International License, which permits use, sharing, adaptation, distribution and reproduction in any medium or format, as long as you give appropriate credit to the original author(s) and the source, provide a link to the Creative Commons licence, and indicate if changes were made. The images or other third party material in this article are included in the article's Creative Commons licence, unless indicated otherwise in a credit line to the material. If material is not included in the article's Creative Commons licence and your intended use is not permitted by statutory regulation or exceeds the permitted use, you will need to obtain permission directly from the copyright holder. To view a copy of this licence, visit http://creativecommons.org/licenses/by/4.0/. 
strokes occurring in those with PFO. The term 'cryptogenic stroke' refers to cerebral ischaemia that has an unexplained or enigmatic cause [5]. 'The cause usually is undetermined because the event is transitory or reversible, investigations did not look for all causes or because some causes are truly unknown' [5]. Despite thorough investigations, including the exclusion of cardiac disease, arterial thromboembolism and prothrombotic states, the causes of such strokes in younger people remain unclear. PFO-related stroke is defined as a separate group of patients in the European position paper on PFO where a $\mathrm{PFO}$ is believed to be involved in the genesis of cerebral ischaemic events [6].

PFOs are commoner amongst cryptogenic strokes than explainable stroke cases. The prospective association of PFO with stroke risk is inconsistent since about a third of PFO in the setting of a stroke are incidental. This makes it difficult to establish a causal relationship between the two [7, 8]. Moreover, population based studies have shown no association between PFO and prospective risk of stroke $[9,10]$. However, about half of those with cryptogenic strokes have residual shunt across a PFO and paradoxical embolism across the shunt can be a contributory factor [11]. Various risk stratification methods have been developed to predict the risk of repeated strokes in people with PFOs, such as the Risk of Paradoxical Embolism (RoPE) score, which indicates an increased risk of stroke if the score is at least 4 [11]. Even in those with a high risk of recurrent stroke, as determined by the ROPE ranking, the average risk of recurrent stroke is very low, and it is difficult to predict those at elevated risk with certainty.

When compared to age-matched individuals with stroke of know aetiology, younger patients with cryptogenic stroke have a 2.3 -fold increased relative risk of having a PFO [12]. Three-quarters of strokes in young individuals are thus likely to be associated with a PFO unlike $52 \%$ in older individuals. Apart from paradoxic embolism, a large PFO combined with an atrial septal aneurysm causes left atrial dysfunction, resulting in an atrial fibrillation-like physiology that predisposes to systemic embolization, which returns to normal after PFO closure. The presence of a hypermobile septum primum or an atrial septal aneurysm in conjunction with PFO raises the likelihood of an initial stroke by fivefold [7]. Moments of PFO patency are caused by changes in the right atrium's pressure and volume. Though the actual risk of a cryptogenic stroke increases with age, the relative risk decreases as other aetiologies become more prevalent. As a result, there is no conclusive connection between PFO and stroke in the elderly.

\section{Platypnoea-orthodeoxia syndrome}

Platypnoea-orthodeoxia syndrome is a rare disorder in which a PFO causes positional desaturation and breathlessness [13]. When the subjects are in certain positions, a change in the anatomy of the atrial septum enables continuous flow of deoxygenated blood from the inferior vena cava. In the sitting position, desaturation occurs, whilst in the supine position, saturation occurs. The atrial septal anatomy may be distorted due to chest wall deformity or prior chest surgery, such as pneumonectomy. A right-to-left shunt, pulmonary shunt, or ventilation-perfusion mismatch may also be involved [14].

\section{Decompression illness}

PFOs have been associated with decompression sickness amongst divers and high-altitude fliers with a fivefold increased risk in individuals with PFO [14]. There is a fivefold increased risk in divers with PFO than those without PFO and this risk increases with the size of the PFO [14]. During a quick transition from a high to low pressure condition, nitrogen bubbles develop inside the tissues and venous circulation as a result of the sudden shift in pressure [13]. These nitrogen bubbles can embolise into the arterial system in those with undiagnosed shunts if they are not filtered from the blood by pulmonary capillary diffusion. In individuals with PFO, paradoxical embolism of nitrogen bubbles from the venous to the arterial circulation can cause neurological and cutaneous symptoms. The presence of decompression illness in divers despite slow ascent is a sign of a PFO.

\section{Migraine with aura}

Migraine with aura is another interesting disorder for which PFO closure has been performed. This is a common ailment that affects teenagers. It has been linked to right-to-left shunts, especially large PFOs [13]. The movement of vasoactive amines (serotonins, bradykinins) and other proposed substances (PGI2, PGE2 and Angiotensin I) that are normally filtered and metabolised in the lungs into the systemic circulation is thought to be responsible [13]. Another mechanism is the migration of venous microthrombi or emboli into the posterior circulation after passing through the PFO since the occipital lobe is primarily involved in migraine with aura [14].

\section{PFO trials}

The earlier landmark trials on system closure in cryptogenic stroke found that PFO closure had no substantial advantage in cryptogenic stroke patients [15-18]. Increased vascular complications, device thrombosis and atrial fibrillation (AF) were linked to the earlier trials. These trials were underpowered, and they involved a variety of ischaemic cerebral events (lacunar strokes, 
TIAs and peripheral atherothrombotic events) [19]. Many of the patients were at low risk, and there were few strokes during the follow-up period. Other methodological problems that could have skewed the results of these trials include slow randomisation, late randomisation, high cross-over and drop-out rates between treatment arms in some of the trials, as well as the failure to select those with abnormal PFO anatomy. In one of these trials, the use of devices linked to AF, such as the Starflex system, led to the negative outcome [20].

Since then, there have been major advancements in trial design, closure system technology, implementation methods, interventionist knowledge and skills and patient selection. Three studies were published in 2017 and another in 2018, resulting in improvements in PFO management in cryptogenic ischaemic events and changes in national guidelines [18, 21-23]. These trials are discussed below.

\section{The RESPECT I and II trials}

This was a multicenter open label trial in the United States and Canada that included people aged 18 to 60 who had had a cryptogenic stroke in the preceding 9 months $[17,18]$. The study was event driven. After randomisation, the main outcome was a composite of recurrent nonfatal ischemic stroke, fatal ischemic stroke or early death. PFO closure had no significant benefit over medical therapy in the intention-to-treat analysis but PFO closure was superior to medical treatment in the as-treated cohort. Individuals with embolic cortical infarcts and those with adverse PFO morphology benefited more with device closure (large shunts or atrial septal aneurysm). Procedure-related adverse events were modest (4.2 percent) in the RESPECT trial's initial report, and there was no increased risk of AF or device thrombosis [17]. The results of the analysis of the RESPECT I trial was not able to influence clinical recommendations to support PFO closure.

In 2017, the RESPECT II trial was released. The patients were followed for a median of 5.9 years. Recurrent ischaemic stroke risk rates were lower in the closure arm than in the medical therapy arm in the intentionto-treat analysis [18]. Even though the closure arm had more venous thromboembolic events, there was a lower risk of recurrent cryptogenic stroke. The FDA approved the Amplatzer device for PFO closure in recurrent strokes after this report. Individuals with an atrial septal aneurysm and a large right-to-left shunt were more likely to benefit from closure of PFO, according to subgroup analysis of the RESPECT II study [18].

\section{CLOSE study}

This was a three-arm research that enrolled 663 individuals with PFO and cryptogenic stroke under the age of
60 years [21]. In this study, eleven different kinds of occluders were employed, with the Amplatzer device accounting for almost $60 \%$ of them [24]. The participants in this study were middle-aged who had experienced a cryptogenic stroke in the previous 6 months and had a PFO with significant shunt.

There were no strokes in the PFO closure arm, whereas there were 14 strokes in the antiplatelet alone arm. Those with large shunts or an atrial aneurysm benefited the most from device closure. Despite the fact that none of the procedural adverse events resulted in mortality, the PFO closure arm had a substantially higher risk of new onset AF than the antiplatelet alone arm. Within the first month after the PFOs were closed, 91 percent of AF occurred. There was no difference in risk between the antiplatelet and anticoagulation arms in this trial. It is worth noting that within 6 months, nearly $70 \%$ of patients had stopped taking oral anticoagulants. Unfortunately, no results were reported based on the type of device closure prosthesis employed in the study.

\section{Gore REDUCE trial}

This study randomised 664 individuals with cryptogenic stroke, 81 percent of whom had moderate or large interatrial shunts [22]. Patients were randomly assigned to antiplatelet treatment with device closure (GoreHelex or Cardioform Septal Occluder) or antiplatelet treatment alone. There was a lower incidence of ischemic stroke in the PFO closure group than the antiplatelet-only group during the median follow-up of 3 years. The incidence of silent cerebral infarctions, on the other hand, was similar in both arms. The closure arm had a higher incidence of device-related complications including AF.

The majority of occurrences of post-closure AF occurred within 45 days following device closure, with 59 percent of cases resolving within 2 weeks. Recurrent stroke occurred more frequently in individuals who developed $\mathrm{AF}$ in the closure arm. Another intriguing discovery was the lack of interaction between shunt size and the impact of PFO closure therapy in this trial [22]. The trial did not provide clarity on the role of shunt size in stroke risk after PFO closure.

Concerns have been raised concerning the study sponsor's participation in the trial's design and analysis. In addition, during the research, the main endpoint was adjusted to include infarcts on MRI. This might explain why the stroke rates in this study were greater than in prior PFO studies.

\section{Korean DEFENSE PFO}

This is a small open label superiority trial in which 120 middle aged patients with high-risk PFO characteristics who had a cryptogenic stroke in the previous 6 months were randomly assigned to either device closure 
(Amplatzer PFO Occluder) or medical therapy alone (antiplatelet or anticoagulation) over a median 3 year follow up [23]. All of the patients had their PFOs closed successfully. Even though the incidence of silent brain infarction (on MRI) was similar between the two groups, the primary endpoint of stroke occurred only in the medical therapy group, whilst the device closure group did not experience any of the primary endpoint. In this study as well, the device closure group had a higher rate of AF. About $80 \%$ of the strokes in the medical arm occurred in those who had an atrial septal aneurysm or atrial septal hypermobility, confirming the high-risk associated with PFOs of such morphology.

\section{Why is there discrepancy between the earlier and recent trials?}

The early trials had varying inclusion criteria which did not allow for recruitment of a homogeneous population whilst the recent trials had more refined patient selection and enroled patients whose index strokes were more likely to be attributed to embolism via a PFO. The GORE REDUCE trial had very strict inclusion criteria. CLOSE recruited patients with echocardiographic features of large or moderate shunts who were more likely to benefit from device closure and were thus able to achieve zero stroke outcome in the device arm during the long period of follow-up. The initial negative result in the first report of the RESPECT trial despite the strict inclusion criteria in this trial could be due to the very rare recurrent stroke event rate in the first few years of follow-up. These new trials underscore the need for good patient selection in clinical trials to identify individuals who are more likely to benefit from PFO closure. There is currently no long-term evidence on the advantages of PFO closure, but it is hoped that the stroke reduction with device closure would last beyond 10 years. In the early trials unlike the recent positive trials, many types of occluders were used and this made it difficult to ascertain benefit. There was also high loss to follow-up in the early trials.

A meta-analysis of the six studies indicated that PFO closure reduced the risk of stroke by $60 \%$ [25]. This was particularly true in people under the age of 60 who had a large right-to-left shunt. It is uncertain if PFO occluder implantation benefits people over 60 years old or those with smaller shunts. Mojadidi et al. [26] conducted another meta-analysis of 3440 patients from all the major studies, and reported a $58 \%$ relative risk reduction in recurrent stroke with PFO closure, even though, there was a higher risk of AF with PFO closure than medical therapy. This risk of AF was device dependent and was nonsignificant in those who had the Amplatzer device inserted.
The 2017 Canadian guidelines recommend PFO closure in addition to long term antiplatelet therapy [27]. Although the European Stroke Organisation has been more liberal with device closure, the NHS England did not change its national recommendations in favour of PFO closure until recently following the publication of favourable cost-effectiveness analysis [27, 28].

\section{Limitations of the trials}

Many of the trials were open label in design. The number of disabling strokes was either very low or not reported. Furthermore, in several of the studies, including the good trials, the number needed to treat (NNT) to avoid a stroke was rather high. Many of individuals who fit the criteria for cryptogenic stroke had other vascular risk factors that might contribute to stroke in ways other than through a PFO. The RoPE (Risk of Paradoxical Embolism) score is a valuable tool for predicting the role of a PFO in stroke risk in such individuals as discussed in the 'Patient selection for PFO closure' section below. A RoPE score of 7 identifies patients who are more likely to benefit from closure and indicated good selection of patients for PFO closure $[29,30]$. It is also likely that the risk of PFO closure is higher under real-world conditions and different from clinical trial conditions.

The recent trials which showed the benefit of PFO closure developed inclusion criteria that made it possible to recruit a significant proportion of participants with adverse PFO anatomy. In the context of unfavourable PFO anatomy, it appears that young patients with cryptogenic strokes would benefit more from device closure. Real-world experience with PFO closure in persons older than the age groups enrolled in the major PFO studies is needed. Von Klemperer et al. [31] reported that stroke physicians were more likely to consider age as a factor in the association of PFO with stroke even though many experts support selective PFO closure in cryptogenic strokes.

\section{What do the trials tell us about the different closure devices?}

The Starflex occluder, the Amplatzer PFO occluder and the Helex occluder were the most often employed occluders in the six RCTs. In a study published in 2013, Hornung et al. [32] compared these three occluders. The rate of closure approached $100 \%$ after 5 years of followup. The Helex occluder had a lower closure rate than the other two occluders. The use of the Helex occluder resulted in a higher rate of second occluder implantation. When the Helex system was used, there were more embolisms. The Starflex occluder was associated with a higher rate of AF than the other two occluders (12.3 percent vs. 3.6 percent for Amplatzer and 2.3 percent for Helex, $p<0.001$ ). With the use of the Starflex 
device, there were more occluder related thrombi (15 percent vs. 6 percent with Amplatzer and 0.5 percent with Helex, $p<0.001)$. The Amplatzer device, on the other hand, outperformed the other devices in terms of preventing recurrent cerebral ischaemia, mortality from a neurologic cause or paradoxical embolism.

Stortecky et al. [20], in a network metanalysis of the CLOSE, PC and RESPECT trials compared the three devices. After 6 months of device implantation, the rate of closure with the different devices was $85.9-95.9 \%$ for Amplatzer, 93.5-95.9\% for Starflex and 86.1-94.5\% for Helex device. The risk of atrial fibrillation was likewise greater with the Starflex device compared with the other devices. The rate of ischemic strokes following device closure was considerably lower with the Amplatzer device in this study. In comparison to the other two occluders, Amplatzer was the most successful in preventing ischemic strokes. In this same study, successful device implantation was achieved in close to $100 \%$ of device closure procedures, with the Helex and Amplatzer devices performing better than the Starflex device. In terms of efficacy and safety, these studies imply that disc occluders are superior than non-disc occluders. They also show that the Amplatzer device has a lower risk of device failure and $\mathrm{AF}$ which has made it popular globally.

\section{Concerns with device closure and device safety}

Despite the close link between PFOs and cryptogenic strokes, not all cryptogenic strokes associated with a PFO are caused by the PFO. The occurrence of a PFO in middle-aged people with traditional cardiovascular risk factors or minor subcortical infarcts does not mean that the PFO is a causal factor for the stroke. There are clues which suggest the likelihood of a PFO being the cause of a paradoxic embolic event. Stroke at high altitude or during decompression or diving points to a PFO being a likely cause [24]. Stroke that occurs shortly after Valsalva manoeuvre or during sleep may also be a pointer. The trials have shown that the risk of cerebral ischaemic events is higher in the presence of atrial septal aneurysm or a large PFO with significant shunt.

However, device closure is not without its risks. In both the CLOSE trial [21] and GORE-REDUCE trial [22], there was increased risk of device complications and AF following PFO closure. Incidence of transient palpitations, vascular access bleeding, infection, erosion of device into the pericardium or aorta and thrombosis on devices (very low, $<1 \%$ with Amplatzer device) have been reported. In the CLOSURE I trial [15], there was increased incidence of device thrombosis. Vascular access complications have been reported in $3.2 \%$ of cases. In the Gore REDUCE trial, serious device-related adverse events including AF occurred more frequently in the PFO closure arm [22].
AF was 2-5 times more likely to occur after device closure. Post closure AF is a real concern and is device dependent with the risk higher in Gore devices, followed by Starflex and is least with the Amplatzer device [19]. This was more common in the GORE REDUCE trial (6.6\%) and the CLOSURE I study which used the STARFlex device (5.7\%), and in the RESPECT trial, AF occurred in $0.25 \%$ in 3141 patient-years after device implantation in contrast to $0.15 \%$ in 2669 patient-years in the medical therapy arm [17]. Most AF occurred in the early postoperative period (within first 6 weeks) and usually resolved spontaneously or with medical therapy [33]. In one study, only $3.9 \%$ of AF post-closure progressed to permanent AF [34].

Even though the procedural risk of new onset AF has been reported as transient, it remains unclear whether this risk might be more durable in some patients. This will have an influence on young patients' decisionmaking when it comes to avoiding antithrombotic medication. Furthermore, the significance of anticoagulation in cryptogenic stroke and the duration of dual antiplatelet treatment following device closure are still unknown. The ADAPTABLE trial [35] is poised to answer some of these questions. Staubach et al. [34] have proposed that the mechanisms of atrial arrhythmogenesis may be due to intrinsic patient-related factors (e.g. older age, hypertension and obesity), and irritation of the atrial wall by the device (most commonly observed with the Starflex occluder which is now rarely used) with attendant electrical obstruction that may facilitate reentry circuits in either of the atria.

There is need for prolonged cardiac monitoring beyond 30 days post closure so that hitherto undiagnosed AF can be easily picked and treated [19]. It is also unclear whether such AF predated device closure or not. The value of electrocardiographic monitoring preferably loop recording for 1-3 months or a 24-h Holter cannot be overemphasised since unmasking occult $\mathrm{AF}$ would require long-term anticoagulation and not PFO closure. Extended cardiac monitoring is superior to 24-h electrocardiographic monitoring for detecting co-existing AF in cryptogenic strokes. Sadly, the use of prolonged electrocardiographic monitoring to rule out undiagnosed AF in cryptogenic strokes was not a criterion in any of the PFO closure trials. There is need for more research to aid the understanding of the long-term prognostic outcomes of AF after device closure and the value of prolonged cardiac monitoring in this setting.

Chest pain has been reported in observational studies on device closure [36, 37]. This is probably due to enhanced inflammatory response to the devices or may even be due to allergy to nickel in the devices (especially the Amplatzer occlude) resulting in excessive scar tissue formation. Interestingly, in the PC and RESPECT trials, 
there was no increased incidence of chest pain in the PFO closure arm when compared with the medical therapy arm. In a survey of more than 14,000 PFO closure procedures, the incidence of device removal due to persistent chest pain was 1:500 [19]. Other reported complications of PFO closure include cardiac tamponade, pulmonary embolism, device migration and access site vascular bleeding.

\section{Evolution of guidelines}

In the German DGN guidelines of 2018, the recommendation for PFO closure with occluders was moved to level A, Evidence level I [38]. Percutaneous PFO closure is recommended by European guidelines in carefully selected patients aged 18 to 65 years who have had a confirmed cryptogenic stroke, transient ischaemic attacks, or systemic embolism and a high probability of the PFO playing a causal role as determined by clinical, anatomical, and imaging features [6]. In individuals with high risk PFO morphology, the evidence is stronger for PFO closure [6]. In such settings, the risk-benefit ratio is more in favour of the Amplatzer device for percutaneous closure.

Until 2012, The National Institute for health and Care Excellence (NICE) approved PFO closure for those with paradoxical embolism. However, uncertainty about the benefit of PFO closure in the earlier trials and its cost effectiveness led to the withdrawal of routine commissioning of PFO closure by NHS England until 2019 when a recent cost-effectiveness analysis in the UK showed that PFO closure is cost-effective in preventing recurrent cryptogenic strokes [28].

\section{Patient selection for PFO closure}

It is often difficult to conclude that a PFO is the cause of a stroke. Furthermore, the risk of recurrent stroke is frequently modest (1 to $2 \%$ ), and the number of people who need to be treated to avoid a stroke is substantial (about 40 to 45) [38]. The diagnosis of cryptogenic stroke in the presence of a PFO should be made by a multidisciplinary team that includes a neurologist, cardiologist, physiotherapists and imaging experts. It is preferable to refer children under the age of 15 to a children's cardiac surgery centre, where they may be evaluated by multidisciplinary teams (MDTs). Bubble contrast transthoracic echocardiography, with provocative procedures to open a PFO that has no right-to-left shunt at rest, should be performed in strokes and transient ischaemic attacks (TIAs) when a PFO is suspected [6]. Diagnoses can also be made with transoesophageal echocardiography and bubble contrast transcranial Doppler.

The difficulties in attributing PFO as the true cause of unexplained stroke led to the creation of a prediction score for cryptogenic stroke, the RoPE (Risk of Paradoxical Embolism) score. The RoPE score is used for triaging patients in this case to determine individuals whose stroke is most likely caused by PFO [24]. The development of this score is based on data of more than 3600 patients with cryptogenic stroke who had transoesophageal echocardiography or transcranial Doppler confirmed PFO [39]. PFO prevalence has been consistently linked to younger age, the absence of typical cardiovascular risk factors and the presence of a superficially placed lesion $[39,40]$. A high score indicates a high possibility of the index stroke being caused by a PFO. Individualised assessment is required for those with a RoPE score of less than 7. Hypercoagulable conditions, atherosclerotic disease, cardioembolic disease and unexplained AF must all be ruled out. The RoPE score does not make any assumption about PFO features, e.g. shunt size or anatomy. The RoPE score calculator is shown in Table 1.

Selection of appropriate patients is critical when planning PFO closure. These are young individuals (under 60 years old) who have had a prior cryptogenic stroke and have significant shunts, septal aneurysms, eustachian valves or Chiari networks. Such strokes or TIAs must have clinical and imaging evidence to support the diagnosis [28]. Imaging usually shows multifocal cerebral lesions. A modified Rankin scale of 3 or less is commonly used by clinicians when selecting those who may benefit from PFO closure [28]. There must also be no significant background atrial fibrillation warranting anticoagulation [28]. Individuals with other indications for long-term anticoagulation, e.g. pulmonary embolism are less likely

Table 1 Risk of Paradoxical Embolism Score (RoPE) calculator $[39,41]$

\begin{tabular}{ll}
\hline Patient characteristic & Points \\
\hline No history of hypertension & 1 \\
No history of diabetes mellitus & 1 \\
No history of stroke or TIA & 1 \\
Nonsmoker & 1 \\
Cortical infarct on brain imaging & 1 \\
Age, years & \\
$18-29$ & 5 \\
$30-39$ & 4 \\
$40-49$ & 3 \\
$50-59$ & 2 \\
$60-69$ & 1 \\
$\geq 70$ & 0 \\
Total RoPE score possible & $0-10$ \\
\hline $\begin{array}{l}\text { A ROPE score of 7 identifies patients who are more likely to benefit from } \\
\text { closure and indicated good selection of patients in studies. Clinical judgement } \\
\text { is still required in decision-making } \\
\text { TIA Transient ischaemic attacks }\end{array}$
\end{tabular}


to be considered good candidates for PFO closure. In the elderly above 60 years old, the benefit of PFO closure remains uncertain and an individualised approach is recommended. A suggested algorithm for PFO closure is shown in Fig. 1 below.

\section{Other PFO closure indications}

In a case series, PFO closure was demonstrated to be effective in the platypnoaea-orthodeoxia syndrome with right-to-left shunt [42]. In a cohort of 683 patients, Mojadidi et al. [43] have shown the effectiveness of PFO closure in such individuals, with almost two-thirds of the patients seeing improvement in hypoxaemia after PFO closure. In the absence of strong evidence from randomised trials, PFO closure can be considered using an individualised approach especially in the setting of severe hypoxia once primary lung disease has been excluded.
Decompression illness is five times more likely in divers with PFO than those without PFO, and the risk increases with the size of the PFO [14]. The occurrence of decompression illness despite slow ascent in divers is a pointer to a PFO. PFO closure has been performed in such individuals with symptomatic decompression illness who have neurologic sequelae especially if the individuals planned to continue diving at deeper depth. In a case control study in which the Occlutech Figulla PFO occluder (Occlutech GmBH, Jene, Germany) was used for PFO closure in divers, after a test dive, there was no change in the appearance of venous bubbles on transthoracic echocardiography in either cases or controls [44]. A longitudinal randomised study of divers who had PFO closure compared with divers without PFO closure showed reduction in neurological events and brain lesions in those who had their PFO closed [45]. It may thus be sensible to advise divers with PFO and decompression sickness to stop diving whilst taking an

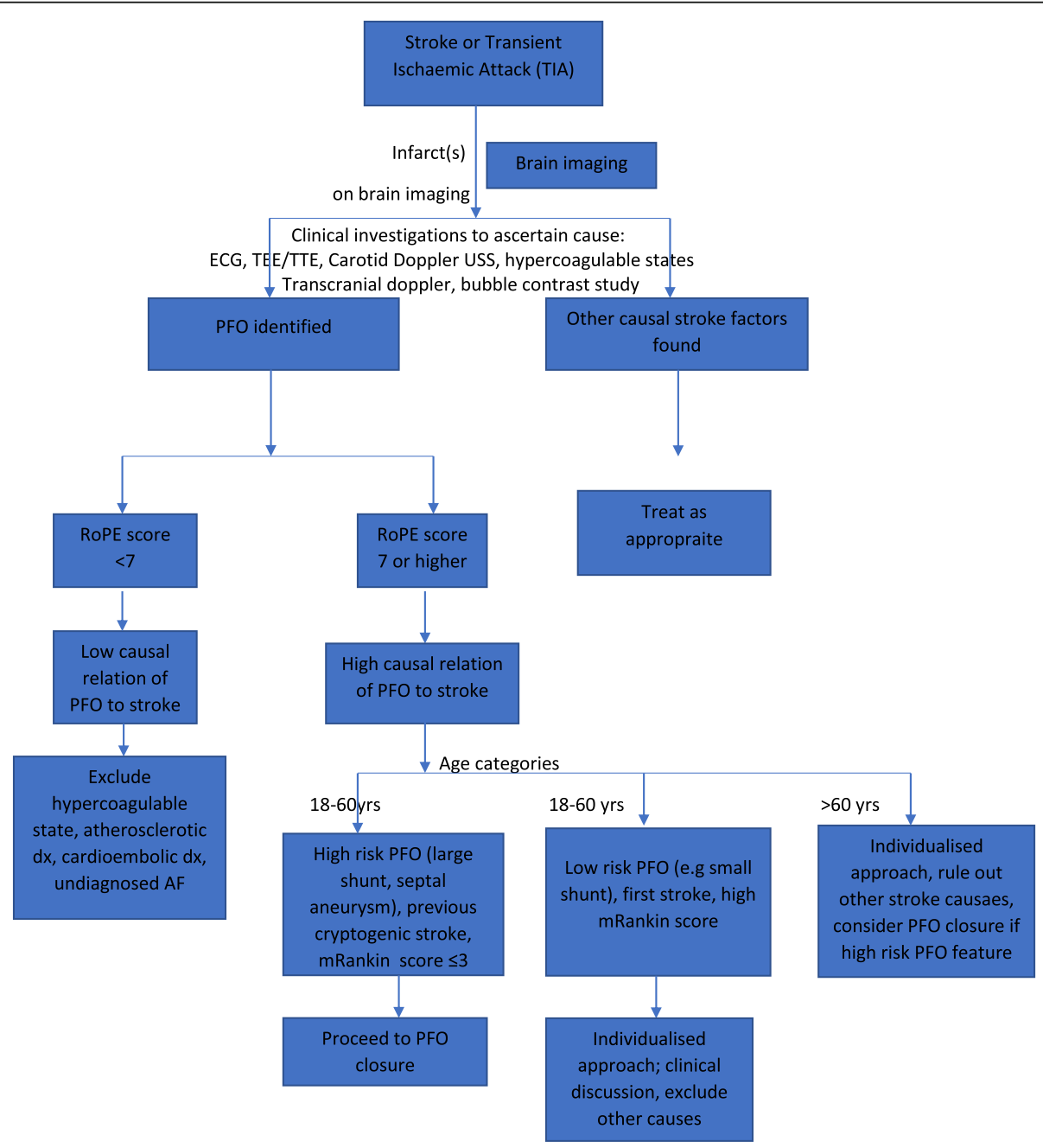

Fig. 1 Suggested algorithm for closure of PFO in individuals with cryptogenic stroke 
individualised approach to PFO closure. This can be explored further in future trials.

PFO closure for migraine with aura remains controversial. Even though it is unclear if there is a causative association between PFOs and migraine headaches, nonrandomised retrospective studies of PFO closure in such situations have indicated improvement in symptoms following PFO closure [46-49]. There is a theoretical benefit of PFO closure in migraineurs especially those with aura in reducing cognitive impairment and stroke risk [48]. In the MIST [50], PRIMA [51] and PREMIUM [52] trials, there was no remarkable benefit.

\section{Common PFO closure devices}

PFO closure device technology and use has spanned about 3 decades. Three PFO occluders featured in the initial clinical trials. These are the Starflex Septal occluder (NMT Medical Inc., Boston, Massachusetts), the Gore Septal Occluder and the Amplatzer device.

The Amplatzer occluder is a self-centering nitinol mesh double disc which has polyester fabric inside the two discs. Within the delivery sheath, these devices are folded like two umbrellas joined at the tip. They are transcatheter-based devices and are deployed under echocardiographic guidance or intracardiac ultrasound. The Amplatzer and Gore Cardioform septal occluders are particularly suitable for long tunnel-shaped PFOs.

The three devices are compared in Table 2 below. The devices are shown in Fig. 2.

\section{Novel PFO closure technologies}

The development of novel 'deviceless' PFO closure technology may help to limit the amount of foreign material used for closure especially in those with complex PFO morphologies and other intracardiac shunts. Selfcentering devices like the SolySafe ${ }^{\mathrm{TM}}$ Septal occluder (delivered over a guidewire), Occlutech PFO occluder (has no atrial limb) and the Atriasept $\mathrm{II}^{\mathrm{TM}}$ PFO occluder (new generation Cardia occluder family) can be used for simultaneous PFO and atrial septal defect (ASD) closure.

The Occlutech Figulla Flex II device was tested in the OPPOSE registry of 100 predominantly middle-aged patients in 8 UK centres [53]. The primary endpoint in this study was PFO closure at 6 months. Implantation was successful in all the patients. The primary endpoint occurred in $79.3 \%$ of the patients. There was a single case of each of device embolization, major bleeding and need for vascular surgery. This device is thus, safe and effective.

Bio-absorbable devices, such as the Biostar device, are gaining popularity in Canada and Europe. The polyester material scaffold that forms the two atrial discs is replaced with acellular collagen that is resorbed over time in this case. Intramural closure technique, in which the septum primum is maintained against the septum secundum by a device that remains in the tunnel, is another alternative. There is no double disc design here, and the inter-atrial septal morphology is preserved with minimum device exposure to native atrial tissue. The CoherexStent $^{\mathrm{TM}}$ EF PFO closure system (Coherex medical Inc., UT, USA) is an example of this and has a selfexpanding nitinol wireframe that is held within the PFO tunnel by anchors in both atriums. It contains a polyurethane foam intra-tunnel portion that is meant to encourage endothelialisation inside the tunnel. Another new device for PFO closure is Nit-Occlud. It features a nitinol double disc and a synthetic patch on both atrial sides to help close the defect. It comes in a variety of sizes.

Noble Stitch (Noble's Medical Technology, CA, USA) is a 'device-less' closure device that uses transcatheter suture technology reminiscent of vascular access

Table 2 Comparison of common PFO closure devices [3, 4, 32]

\begin{tabular}{|c|c|c|c|}
\hline Features & Amplatzer & CardioSEAL STARflex & Gore devices \\
\hline Country/region of use & Most used worldwide & USA & $\begin{array}{l}\text { USA, UK, Canada, Finland, Norway and } \\
\text { Sweden }\end{array}$ \\
\hline Hybrid function & No & No & Yes \\
\hline Device material & $\begin{array}{l}\text { Double disc with nitinol mesh. Has } \\
\text { polyester fabric inside the discs. }\end{array}$ & $\begin{array}{l}\text { Two nitinol cross bars fixed to } \\
\text { square Ivalon patches }\end{array}$ & $\begin{array}{l}\text { Polytetrafluoroethylene patch material } \\
\text { with hydrophilic coat } \\
\text { Protection offered by a nitinol elastic } \\
\text { wire frame on a double disc }\end{array}$ \\
\hline Self-centering & Yes & No & No \\
\hline PFO closure success & $98.6 \%$ & $96.8 \%$ & $91.8 \%$ \\
\hline Thrombosis risk & $\downarrow$ & $\uparrow$ & $\downarrow$ \\
\hline Atrial fibrillation risk & $\downarrow$ & $\uparrow$ & $\downarrow$ \\
\hline $\begin{array}{l}\text { Recurrent neurological } \\
\text { events post closure }\end{array}$ & $\downarrow$ & $\uparrow$ & $\downarrow$ \\
\hline $\begin{array}{l}\text { Suitability for long tunnel- } \\
\text { shape PFOs }\end{array}$ & Yes & No & Yes \\
\hline
\end{tabular}


A

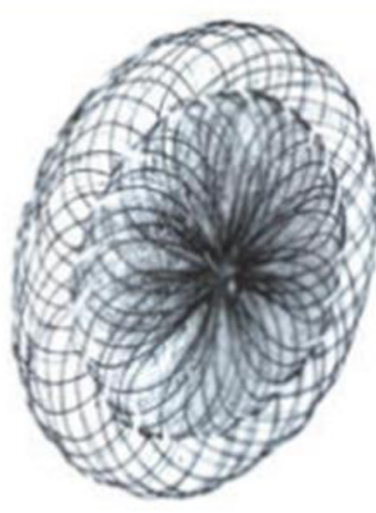

B.

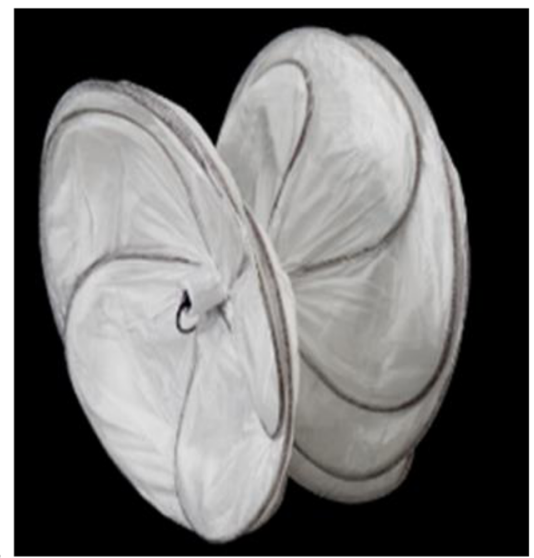

C.

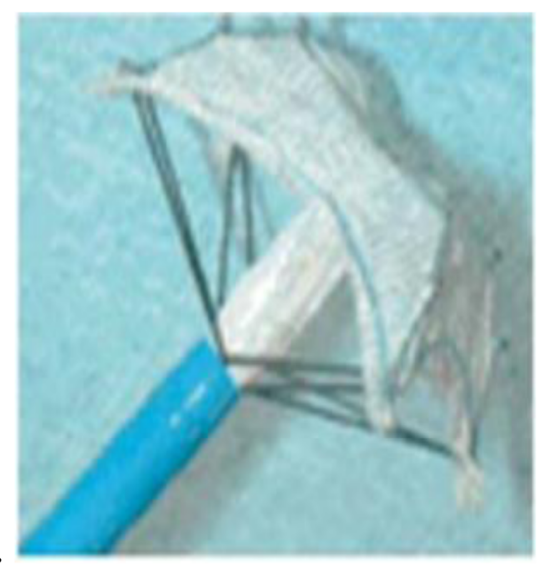

Fig. 2 Common PFO closure devices. A Amplatzer device. B Gore CARDIOFORM Septal occluder. C STARflex device

suturing devices. To close the septum, this requires puncturing each septum independently and tying a knot with a needle to approximate the septum primum to the septum secundum. This has only been used in a few places in the USA. The HeartStitch ${ }^{\mathrm{TM}}$ is a device comparable to the Noble Stitch that consists of polypropylene sutures and two separately deployed needles.

The PFx ${ }^{\mathrm{TM}}$ Closure System brings the septum primum and secundum together using radiofrequency. It is really 'device-free', and closure rates of up to $90 \%$ have been observed in PFOs smaller than $4 \mathrm{~mm}$. Another device for PFO closure is the SeptRx ${ }^{\mathrm{TM}}$ occluder. It lengthens the septum primum to bring it closer to the septum secundum. It requires very little material and does not change the shape of the septum primum. It is also radiopaque, so imaging can quickly confirm its successful deployment. In pre-clinical investigations, the BioTREK $^{\mathrm{TM}}$ is a totally bio-absorbable septal device. It employs bioabsorbable polymers and is less inflammatory.

The details of these novel devices are summarised in Table 3.

Table 3 Novel PFO closure technologies [3]

\section{Features}

\footnotetext{
Novel devices and countries

A. Bio-absorbable devices

Biostar (Europe and Canada) First human trial done in the UK

BioTREK $^{\text {TM }}$

Still in preclinical phase

B. Intramural device

Coherex FlatStent ${ }^{\mathrm{TM}}$ EF (Coherex

Medical Inc., UT, USA)

Animal studies ongoing.

C. Single wire device

Nit-Occlud PFO device

Available in Poland and the US

D. 'Device-less' technologies

Noble Stitch (Noble's Medical

Technology, CA, USA)

Reported experience in Italy and the US

HeartStitch $^{\text {TM }}$

Used in US, approved in Europe

PFx ${ }^{\text {TM }}$ Closure device

Available in Europe

SeptRx ${ }^{\text {TM }}$ Occluder (SeptRx, Inc., Fremont, California)

First human trial in Germany
}

The polyester material scaffold of the two discs in traditional devices is replaced with acellular collagen.

Fully bio-absorbable septal device. Less inflammatory and uses bioabsorbable poly-4-hydroxybutyrate polymers produced by recombinant DNA technology

The intra-tunnel unit holds the septum primum and septum secundum together. Preserved septal anatomy. Low thrombosis risk.

Reduced thrombosis Rapid endothelialisation. Pre-mounted, retrievable, and easy to use. Closure is effected by a synthetic patch on both atrial sides.

Transcatheter suture technology.

Sutures made of polypropylene and two needles that may be deployed separately

Septum primum and secundum are apposed using radiofrequency. Real device-less technology.

Ideal for long tunnel PFOs.

Inserted within PFO tunnel. Brings both septum primum and septum secundum together. Correct placement can be verified with imaging as it is radioopaque. 


\section{Conclusion}

PFOs increase the risk of cryptogenic strokes in young individuals and the recent trials have demonstrated that PFO device closure is more effective than traditional medical therapy in preventing recurrent strokes, particularly in individuals with large shunts or accompanying atrial septal aneurysms. The ROPE score is crucial for achieving excellent results in individuals undergoing PFO closure evaluations. There is an increased incidence of periprocedural AF, which merits additional investigation. New 'device-less' devices are increasingly being employed in conjunction with minimal material implantation, decreasing the requirement for long-term anticoagulation.

\section{Abbreviations}

AF: Atrial fibrillation; ASD: Atrial septal defect; MDT: Multidisciplinary teams; NNT: Number needed to treat; PFO: Patent foramen ovale; RoPE score: Risk of Paradoxical Embolism score; TIA: Transient ischaemic attacks

\section{Acknowledgements}

Not applicable

\section{Authors' contributions}

ASO and MSO conceptualised the study; both authors conducted the review of the literature for this work. ASO wrote the initial draft. All authors read and approved the final manuscript.

\section{Funding}

This work was self-funded by the authors.

\section{Availability of data and materials}

Not applicable

\section{Declarations}

Ethics approval and consent to participate

Not applicable

\section{Consent for publication}

Not applicable

\section{Competing interests}

The authors declare that they have no competing interests.

\section{Author details}

${ }^{1}$ Nuffield Department of Population Health, University of Oxford, Oxford, UK. 2Division of Cardiology, Department of Medicine, University College Hospital, Ibadan, Nigeria. ${ }^{3}$ Department of Child Dental Health, University of Medical Sciences Teaching Hospitals Complex, Ondo, Ondo State, Nigeria.

Received: 3 March 2021 Accepted: 24 June 2021

Published online: 09 August 2021

\section{References}

1. Meier B, Lock JE (2003) Contemporary management of patent foramen ovale. Circulation. 107(1):5-9. https://doi.org/10.1161/01.CIR.0000046073.342 61.C1

2. Hagen P, Scholz D, Edwards W (1984) Incidence and size of patent foramen ovale during the first 10 decades of life: an autopsy study of 965 normal hearts. Mayo Clin Proc. 59(1):17-20. https://doi.org/10.1016/S0025-6196(12 60336-X

3. Spies C, Hijazi ZM (2010) Transcatheter patent foramen ovale closure: review and choice of devices. Interv Cardiol. 2(4):601-614. https://doi.org/10.2217/ ica.10.53
4. Ko R, Walker NE, Mullen MJ (2010) Different patent foramen ovale closure techniques in varying anatomies. Interv Cardiol. 2(1):85-95. https://doi.org/1 $0.2217 /$ ica.09.36

5. NHS Commissioning Board Clinical Reference Group for Specialised Cardiology. NHS Commissioning Board clinical commissioning policy statement: patent foramen ovale (PFO) closure. 2013.

6. Pristipino C, Sievert H, Ascenzo FD, Mas JL, Meier B, Scacciatella P et al (2019) European position paper on the management of patients with patent foramen ovale. General approach and left circulation thromboembolism. Eur Heart J. 40(38):3182-3195. https://doi.org/10.1093/ eurheartj/ehy649

7. Rigatelli G, Aggio S, Cardaioli P, Chinaglia M, Rigatelli G, Roncon L et al (2009) Left atrial dysfunction in patients with patent foramen ovale and atrial septal aneurysm. J Am Coll Cardiol Intv 2(7):655-662 Available from: https://doi.org/10.1016/j.jcin.2009.05.010

8. Alsheikh-ali AA, Thaler DE, Kent DM (2009) Patent foramen ovale in cryptogenic stroke incidental or pathogenic? Stroke. 40(7):2349-2355. https://doi.org/10.1161/STROKEAHA.109.547828

9. Meissner I, Khandheria BK, Heit JA, Petty GW, Sheps SG, Schwartz GL, Whisnant JP, Wiebers DO, Covalt JL, Petterson TM, Christianson TJH, Agmon Y (2006) Patent foramen ovale: innocent or quilty? Evidence from a prospective population-based study. J Am Coll Cardiol. 47(2):440-445 Available from: https://doi.org/10.1016/j.jacc.2005.10.044

10. Di Tullio MR, Sacco RL, Sciacca RR, Ng ESCD, Jin Z, Homma S (2007) Patent foramen ovale and the risk of ischemic stroke in a multiethnic population. J Am Coll Cardiol. 49(7):797-802. https://doi.org/10.1016/j.jacc.2006.08.063

11. Ghosh S, Ghosh AK, Ghosh SK (2007) Patent foramen ovale and atrial septal aneurysm in cryptogenic stroke. Postgr Med J. 83(977):173-177. https://doi. org/10.1136/pgmj.2006.051094

12. Abdelghani M, El-Shedoudy SA, Nassif M, Bouma BJ, de Winter RJ (2019) Management of patients with patent foramen ovale and cryptogenic stroke: an update. Cardiology. 143(1-2):62-72. https://doi.org/10.1159/000501028

13. Giblett JP, Abdul-samad O, Shapiro LM, Rana BS, Calvert PA (2019) Patent foramen ovale closure in 2019. Interv Cardiol Rev. 14(1):34-41. https://doi. org/10.15420/icr.2018.33.2

14. Collado FMS, Poulin M, Murphy JJ, Jneid H, Kavinsky CJ (2018) Patent foramen ovale closure for stroke prevention and other disorders. J Am Hear Assoc. 7(e007146):1-22

15. Furlan AJ, Reisman M, Massaro J, Mauri L, Adams H, Albers GW, Felberg R, Herrmann H, Kar S, Landzberg M, Raizner A, Wechsler L (2012) Closure or medical therapy for cryptogenic stroke with patent foramen ovale. N Engl J Med. 366(11):991-999. https://doi.org/10.1056/NEJMoa1009639

16. Meier B, Kalesan B, Mattle HP, Khattab AA, Hildick-Smith D, Dudek D, Andersen G, Ibrahim R, Schuler G, Walton AS, Wahl A, Windecker S, Jüni P (2013) Percutaneous closure of patent foramen ovale in cryptogenic embolism. N Engl J Med. 368(12):1083-1091. https://doi.org/10.1056/ NEJMoa1211716

17. Carroll JD, Saver JL, Thaler DE, Smalling RW, Berry S, MacDonald LA et al (2013) Closure of patent foramen ovale versus medical therapy after cryptogenic stroke. N Engl J Med. 368(12):1092-1100. https://doi.org/10.1 056/NEJMoa1301440

18. Saver JL, Carroll JD, Thaler DE, Marks DS, Tirschwell DL (2017) Long-term outcomes of patent foramen ovale closure or medical therapy after stroke. N Engl J Med. 377(11):1022-1032. https://doi.org/10.1056/NEJMoa1610057

19. Mojadidi MK, Zaman MO, Elgendy IY, Mahmoud AN, Patel NK, Agarwal N, Tobis JM, Meier B (2018) Cryptogenic stroke and patent foramen ovale. J Am Coll Cardiol. 71(9):1035-1043. https://doi.org/10.1016/j.jacc.2017.12.059

20. Stortecky S, Costa BR, Mattle HP, Carroll J, Hornung M, Sievert H et al (2015) Percutaneous closure of patent foramen ovale in patients with cryptogenic embolism: a network meta-analysis. Eur Heart J. 36(2):120-128. https://doi. org/10.1093/eurheartj/ehu292

21. Mas J-L, Derumeaux G, Guillon B, Massardier E, Hosseini H, Mechtouff L, Arquizan C, Béjot Y, Vuillier F, Detante O, Guidoux C, Canaple S, Vaduva C, Dequatre-Ponchelle N, Sibon I, Garnier P, Ferrier A, Timsit S, RobinetBorgomano E, Sablot D, Lacour JC, Zuber M, Favrole P, Pinel JF, Apoil M, Reiner P, Lefebvre C, Guérin P, Piot C, Rossi R, Dubois-Randé JL, Eicher JC, Meneveau N, Lusson JR, Bertrand B, Schleich JM, Godart F, Thambo JB, Leborgne L, Michel P, Pierard L, Turc G, Barthelet M, Charles-Nelson A Weimar C, Moulin T, Juliard JM, Chatellier G (2017) Patent foramen ovale closure or anticoagulation vs. antiplatelets after stroke. N Engl J Med. 377(11):1011-1021. https://doi.org/10.1056/NEJMoa1705915 
22. Søndergaard L, Kasner SE, Rhodes JF, Andersen G, Iversen HK, Nielsen-Kudsk JE, Settergren M, Sjöstrand C, Roine RO, Hildick-Smith D, Spence JD, Thomassen $L$ (2017) Patent foramen ovale closure or antiplatelet therapy for cryptogenic stroke. N Engl J Med. 377(11):1033-1042. https://doi.org/10.1 056/NEJMoa1707404

23. Lee PH, Song J, Kim JS, Heo R, Lee S, Kim D et al (2018) Cryptogenic stroke and high-risk patent foramen ovale: the DEFENSE-PFO trial. J Am Coll Cardiol. 71(20):2335-2342. https://doi.org/10.1016/j.jacc.2018.02.046

24. Andre C (2019) Endovascular closure of patent foramen ovale: a critical appraisal of published trials. Arq Neuropsiquiatr. 77(10):731-740. https://doi. org/10.1590/0004-282x20190120

25. Goel S, Patel S, Zakin E, Teja R, Gotesman J, Ahmad B et al (2019) Patent foramen ovale closure versus medical therapy for cryptogenic stroke: an updated systematic review and meta-analysis. Indian Heart J. 71(6):446-453. https://doi.org/10.1016/j.ihj.2019.10.002

26. Mojadidi MK, Elgendy AY, Elgendy IY, Mahmoud AN, Elbadawi A, Eshtehardi P, Patel NK, Wayangankar S, Tobis JM, Meier B (2017) Transcatheter patent foramen ovale closure after cryptogenic stroke: an updated meta-analysis of randomized trials. ACC Cardiovasc Interv. 10(21):2228-2230. https://doi.org/1 0.1016/j.jcin.2017.09.002

27. Wein T, Lindsay MP, Co R, Foley N, Berlingieri J, Bhogal S et al (2018) Canadian stroke best practice recommendations: secondary prevention of stroke, sixth edition practice guidelines, update 2017. Int J Stroke. 13(4):420443. https://doi.org/10.1177/1747493017743062

28. NHS England Specialised Services Clinical Reference Group for Cardiac Services. Clinical commissioning policy: percutaneous patent foramen ovale closure for the prevention of recurrent cerebral embolic stroke in adults (around the age 60 years and under). 2019. Report No.: 000826.

29. Prefasi D, Martınez-Sanchez P, Fuentes B, Diez-Tejedor E (2016) The utility of the RoPE score in cryptogenic stroke patients 50 years in predicting a stroke-related patent foramen ovale. Int J Stroke. 11(1):NP7-NP8. https://doi. org/10.1177/1747493015607505

30. Singh A, Ojeanor F, Ahluwalia G, Ananthasubramaniam K (2019) Can the rope score be used as a triaging tool in assessing the need for saline contrast study in stroke workup to identify patent foramen ovale? Circulation 140(Suppl_1):A13375

31. Von Klemperer K, Kempny A, Pavitt CW, Janssen JC, Uebing A, Nicol E (2017) Device closure for patent foramen ovale following cryptogenic stroke: a survey of current practice in the UK. Open Hear. 4(e000636):1-5

32. Hornung M, Bertog SC, Franke J, Id D, Taaffe M, Wunderlich N, Vaskelyte L, Hofmann I, Sievert H (2013) Long-term results of a randomized trial comparing three different devices for percutaneous closure of a patent foramen ovale. Eur Heart J. 34(43):3362-3369. https://doi.org/10.1093/eurhea rtj/eht283

33. Mojadidi MK, Elgendy AY, Elgendy IY, Mahmoud AN, Meier B (2018) Atrial fibrillation after percutaneous patent foramen ovale closure. J Am Col Cardiol [Internet]. 2018;122(5):915. Available from. https://doi.org/10.1016/j.a mjcard.2018.05.035

34. Staubach S, Steinberg DH, Zimmermann W, Wawra N, Wilson N, Wunderlich $\mathrm{N}$, Sievert $\mathrm{H}$ (2009) Atrial fibrillation after patent foramen ovale closure. Catheter Cardiovasc Interv. 74(6):889-895. https://doi.org/10.1002/ccd.22172

35. Jones WS, Roe MT, Antman EM, Pletcher MJ, Harrington RA, Rothman RL, Oetgen WJ, Rao SV, Krucoff MW, Curtis LH, Hernandez AF, Masoudi FA (2016) The changing landscape of randomized. J Am Coll Cardiol. 68(17): 1898-1907. https://doi.org/10.1016/j.jacc.2016.07.781

36. Alizadehasl A, Neshati M, Borj P, Sadeghpour A, Firouzi A, Sanati H (2017) The frequency and importance of chest pain in midterm follow up of transcatheter closure of interatrial septal defect. J Cardiovasc Thorac Res. 9(4):215-220. Available from:. https://doi.org/10.15171/jcvtr.2017.37

37. Knepp MD, Rocchini AP, Lloyd TR, Aiyagari RM (2010) Long-term follow up of secundum atrial septal defect closure with the amplatzer septal occluder. Congenit Hear Dis. 5(1):32-37. https://doi.org/10.1111/j.1747-0803.2009.003 58.x

38. Diener H, Grau A, Baldus S (2019) Cryptogenic stroke and patent foramen ovale (abridged and translated version). Neurol Res Pract. 1(1):1-10. https:// doi.org/10.1186/s42466-019-0008-2

39. Kent DM, Ruthazer R, Weimar C, Angelantonio D, Di Tullio MR, Lutz JS et al (2013) An index to identify stroke-related vs incidental patent foramen ovale in cryptogenic stroke. Neurology. 81(7):619-625. https://doi.org/1 0.1212 WNL.0b013e3182a08d59
40. Yuan K, Kasner SE (2018) Patent foramen ovale and cryptogenic stroke: diagnosis and updates in secondary stroke prevention. Stroke Vasc Neurol 3(e000173):84-91

41. Wiktor DM, Carroll JD. The case for selective patent foramen ovale closure after cryptogenic stroke. Circ Cardiovasc Interv. 2018;11(e004152):1-12, e004152, DOI: https://doi.org/10.1161/CIRCINTERVENTIONS.117.004152.

42. Shah A, Osten M, Leventhal A et al (2016) Percutaneous intervention to treat platypnea-orthodeoxia syndrome: the Toronto experience. JACC Cardiovasc Interv. 9(18):1928-1938. https://doi.org/10.1016/j.jcin.2016.07.003

43. Mojadidi MK, Gevorgyan R, Noureddin N, Tobis JM (2015) The effect of patent foramen ovale closure in patients with platypnoea-orthodeoxia syndrome. Catheter Cardiovasc Interv. 86(4):701-707. https://doi.org/10.1 $002 /$ ccd.25953

44. Honek J, Sramek M, Sefc L, Januska J, Fiedler J, Horvath M et al (2014) Effect of catheter-based patent foramen ovale closure on the occurrence of arterial bubbles in scuba divers. JACC Cardiovasc Interv. 7(4):403-408. https://doi.org/10.1016/j.jcin.2013.12.199

45. Billinger M, Zbinden R, Mordasini R, Windecker S, Schwerzmann M, Meier B, Seiler C (2011) Patent foramen ovale closure in recreational divers: effect on decompression illness and ischaemic brain lesions during long-term followup. Heart. 97(23):1932-1937. https://doi.org/10.1136/heartjnl-2011-300436

46. Wahl A, Praz F, Tai T, Findling O, Walpoth N, Nedeltchev K, Schwerzmann M, Windecker S, Mattle HP, Meier B (2010) Improvement of migraine headaches after percutaneous closure of patent foramen ovale for secondary prevention of paradoxical embolism. Heart. 96(12):967-973. https://doi.org/10.1136/hrt.2009.181156

47. Shi Y-J, Lv J, Han X, Luo G (2017) Migraine and percutaneous patent foramen ovale closure: a systematic review and meta-analysis. BMC Cardiovasc Disord. 17(203):4-9

48. Reisman M, Fuller CJ (2009) Is patent foramen ovale closure indicated for migraine? Circ Cardiovasc Interv. 2(5):468-474. https://doi.org/10.1161/ CIRCINTERVENTIONS.109.876128

49. Jesurum JT, Fuller CJ, Kim CJ, Krabill KA, Spencer MP, Olsen JV, Likosky WH, Reisman M (2008) Frequency of migraine headache relief following patent foramen ovale " Closure " despite residual right-to-left shunt. Am J Cardiol. 102(7):916-920. https://doi.org/10.1016/j.amjcard.2008.05.035

50. Dowson A, Mullen MJ, Peatfield R, Muir K, Khan AA, Wells C, Lipscombe SL, Rees T, de Giovanni JV, Morrison WL, Hildick-Smith D, Elrington G, Hillis WS, Malik IS, Rickards A (2008) Technology (MIST) trial evaluate the effectiveness of patent foramen ovale closure with STARFlex septal repair implant to resolve refractory migraine headache. Circulation. 117(11):1397-1404. https://doi.org/10.1161/CIRCULATIONAHA.107.727271

51. Mattle HP, Evers S, Hildick-smith D, Becker WJ, Baumgartner H, Chataway J et al (2016) Percutaneous closure of patent foramen ovale in migraine with aura, a randomized controlled trial. Eur Heart J. 37(26):2029-2036. https:// doi.org/10.1093/eurheartj/ehw027

52. Tobis JM, Charles A, Silberstein SD, Sorensen S, Maini B, Horwitz PA et al (2017) Percutaneous closure of patent foramen ovale in patients with migraine: the PREMIUM trial. J Am Coll Cardiol [Internet]. 2017;70(22):276674. Available from. https://doi.org/10.1016/j.jacc.2017.09.1105

53. Hildick-Smith D, Williams T, MacCarthy P, Thomson C, Mullen M, Morrison L (2017) Occlutech percutaneous patent foramen ovale closure: safety and efficacy registry (OPPOSE). Int J Cardiol. 245:99-104. https://doi.org/10.1016/ j.ijcard.2017.07.058

\section{Publisher's Note}

Springer Nature remains neutral with regard to jurisdictional claims in published maps and institutional affiliations. 